\title{
Air quality co-benefits of ratcheting up the NDCs
}

\section{Sebastian Rauner ${ }^{1}$. Jérôme Hilaire ${ }^{1,2}$. David Klein ${ }^{1}$ • Jessica Strefler ${ }^{1}$. Gunnar Luderer ${ }^{1}$}

Received: 16 January 2019 / Accepted: 18 January 2020 / Published online: 18 April 2020

(C) The Author(s) 2020

\begin{abstract}
The current nationally determined contributions, pledged by the countries under the Paris Agreement, are far from limiting climate change to below $2{ }^{\circ} \mathrm{C}$ temperature increase by the end of the century. The necessary ratcheting up of climate policy is projected to come with a wide array of additional benefits, in particular a reduction of today's 4.5 million annual premature deaths due to poor air quality. This paper therefore addresses the question how climate policy and air pollution-related health impacts interplay until 2050 by developing a comprehensive global modeling framework along the cause and effect chain of air pollution-induced social costs. We find that ratcheting up climate policy to a $2{ }^{\circ}$ compliant pathway results in welfare benefits through reduced air pollution that are larger than mitigation costs, even with avoided climate change damages neglected. The regional analysis demonstrates that the $2{ }^{\circ} \mathrm{C}$ pathway is therefore, from a social cost perspective, a "no-regret option" in the global aggregate, but in particular for China and India due to high air quality benefits, and also for developed regions due to net negative mitigation costs. Energy and resource exporting regions, on the other hand, face higher mitigation cost than benefits. Our analysis further shows that the result of higher health benefits than mitigation costs is robust across various air pollution control scenarios. However, although climate mitigation results in substantial air pollution emission reductions overall, we find significant remaining emissions in the transport and industry sectors even in a $2{ }^{\circ} \mathrm{C}$ world. We therefore call for further research in how to optimally exploit climate policy and air pollution control, deriving climate change mitigation pathways that maximize co-benefits.
\end{abstract}

Keywords Air pollution $\cdot$ Co-benefits $\cdot$ Climate change $\cdot$ Health impacts

Electronic supplementary material The online version of this article (https://doi.org/10.1007/s10584-020-02699-1) contains supplementary material, which is available to authorized users.

Sebastian Rauner

rauner@pik-potsdam.de

1 Potsdam Institute for Climate Impact Research (PIK), Member of the Leibniz Association, P.O. Box 6012 03, D-14412 Potsdam, Germany

2 Mercator Research Institute on Global Commons and Climate Change (MCC) gGmbH, EUREF Campus 19, Torgauer Str. 12-15, D-10829 Berlin, Germany 
As acknowledged through the Paris Agreement, climate change will require international collective action to limit the global mean temperature increase to well below $2{ }^{\circ} \mathrm{C}$ above preindustrial levels. Economic costs are one of the main concerns of policy makers, who report their planned climate policies in the form of nationally determined contributions. However, the anticipated decarbonization of the economy, and especially the transformation of the energy system, comes with additional benefits and challenges concerning the sustainability dimensions of economy, society, and ecology.

In contrast to economic implications, the evaluation of societal and ecological impacts is often less straightforward and can involve sensible ethical questions, for example with regard to the monetary value of ecosystem services or human health as well as the unclear distribution of costs across different societal groups. Nevertheless, the magnitude of the potential co-benefits of climate mitigation-illustrated for example by the 9 million premature deaths attributable to environmental pollution in 2015, as estimated by Landrigan et al. (2018) — should merit them for consideration in climate policy assessments. Local air pollution is exceptionally notable, as it is responsible for about two-thirds of all premature deaths from environmental pollution (Landrigan et al. 2018). It dwarfs in comparison other causes of avoidable deaths more salient in the public eye (such as the 430,000 annual deaths from interpersonal violence and 170,000 from drug use), as well as causes which receive considerable financial support (1.39 million annual deaths from road accidents) (Wang et al. 2016). Our research therefore contributes to the holistic assessment of climate policies by analyzing the interplay of these policies with air pollution-related health impacts.

Although air pollution has a multitude of negative impacts on the environment (e.g., acid rain, eutrophication) and the economy (e.g., the decrease of capital value, productivity loss from the workforce, crop yield losses), the most relevant in terms of social cost are effects on human health mainly via cardiovascular disease, and others we are just beginning to understand. They range from reduced cognitive performance (Duncan 2014) to an increase in infant mortality (Heft-Neal et al. 2018) and newly discussed impacts on brain health such as the increased risk of dementia (The Lancet Neurology 2018). In the present study, we focus on the most impactful and well-researched health impact, the increased mortality risk due to diseases caused by long-term exposure to concentrations of air pollution.

Analyzing co-benefits of climate change mitigation has received quite some attention from the research community; see Deng et al. (2017) for a general review and Gao et al. (2018) for a public health specific review. Recent literature on the nexus of climate change and air pollution analyzed the effects of different climate and air pollution policy scenarios in terms of reduced pollution concentration levels (Rao et al. 2016), estimated the social costs of air pollution to be comparable with the mitigation cost (West et al. 2013; Vandyck et al. 2018), analyzed the health co-benefits under different distributions of climate change abatement efforts (Rafaj et al. 2012; Markandya et al. 2018), and focused on regional characteristics (Xie et al. 2018; Li et al. 2018). However, the magnitude of these benefits depends on the development of air pollution controls determining the emission factors of technologies as well as socioeconomic trends determining the potentially affected population size. Our research adds to this discussion by introducing a regionally, sectorally, and temporally explicit analysis of the monetized co-benefits relative to the climate policy costs. In contrast to existing literature, we assess different climate policies in combination with air pollution control scenarios with a special focus on the congruent implementation of the spatially explicit socioeconomic features of the scenarios in all of the modeling steps. This is especially important since socioeconomic trends play a crucial role in the development of the Energy-Economy-Climate nexus and for the health impacts of air pollution. Socioeconomic trends not only drive energy demand but also increase the affected population size 
(population growth, demographic change) and concentrate people in high pollution areas (urbanization). We use a common Shared Socioeconomic Pathways (SSP) (O'Neill et al. 2017) scenario, corresponding to the SSP2 pathway.

\section{Methods}

Analyzing the interplay of climate policy and air pollution-related health impacts requires a comprehensive modeling framework along the cause and effect chain of air pollutioninduced health costs, stylized in Fig. 1. We couple state of the art models from the energyeconomy-climate development (REMIND), sector-specific emission factor developments (GAINS), resulting pollutant concentrations through an atmospheric chemistry transport model (TM5-FASST), and spatially explicit socioeconomic trends to estimate the health impacts and their social cost. We apply the framework to the scenario space spanned by climate policy and air pollution legislation.

\subsection{Energy-economy-climate modeling}

The starting point of the model chain is the global energy-economy general equilibrium model REMIND available at https://github.com/remindmodel/remind, linking a macroeconomic growth model with a bottom-up energy system model (Bauer et al. 2008;

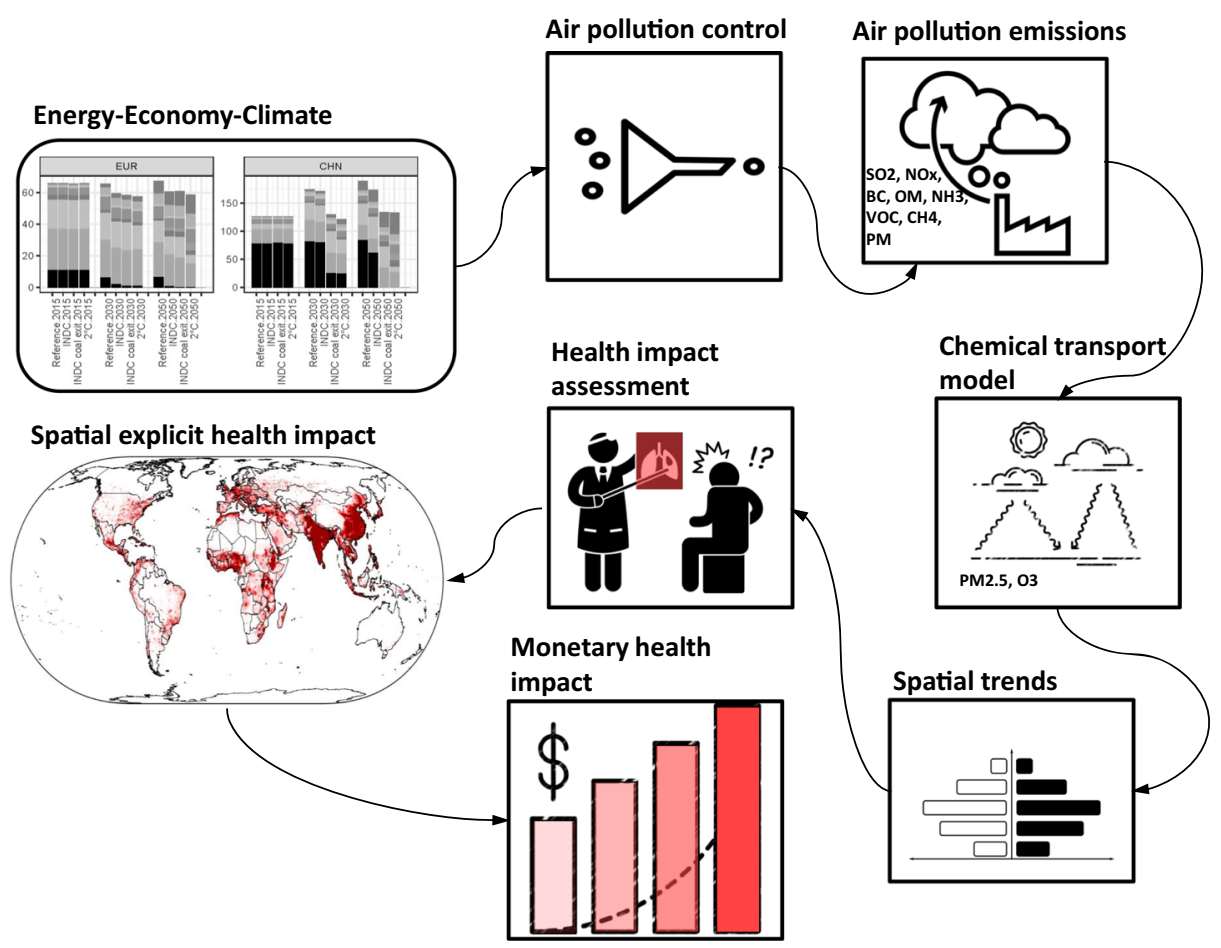

Fig. 1 Modeling framework of the cause effect chain of energy-economy-climate to monetized health impacts of air pollution (symbols from Thenounproject.com) 
Bauer et al. 2012; Leimbach et al. 2010; Luderer et al. 2016). This integrated assessment model is built around a Ramsey-type growth macroeconomic core which maximizes inter-temporal welfare, inducing associated energy demands. These are fulfilled through the energy system model by converting primary to secondary and final energy while considering primary energy resources as well as renewable energy potentials. More than 50 conversion technologies are considered, representing system characteristics, costs, and their respective development. The model accounts for major drivers of energy system inertia and path dependencies by representing full age-specific capacity structure, technological learning, and technology ramping cost. The model is calibrated to a rich data set of historical developments. The implementation of different climate policies in the form of prescribed greenhouse gas (GHG) emission budgets and explicit energy sector policies such as energy-sector fuel taxes and consumer subsidies facilitate the comprehensive assessment of different policy scenarios.

\subsection{Air pollution emissions}

We model the progression of air pollution control through the change of technology-specific aggregated emission factors over time. These are derived from the GAINS model (Amann 2012), encompassing all relevant air pollution species. GAINS projects the air pollution policy goals and their implementation as well as relevant technology research, development, deployment, and diffusion (RDD\&D). We use these projections to construct three air pollution control scenarios further described in 1.6. These GAINS emission factors are then mapped to REMIND activities on final energy level for industry, buildings, and transport, on secondary energy level for electricity, and on primary energy level for fossil fuel production and distribution (see Table SI-3). This ensures a comprehensive modeling of sectoral substitution effects. Non-energy-related emissions are modeled also through activity-specific emission factors where they are included in the REMIND model (industry, agriculture) or taken exogeniously (waste, aviation, and international shipping). This is important where climate policy for example leads to higher biomass demand and emissions. Bulk materialsrelated emissions, available in GAINS, are included by scaling with economic output where no specific activity is available in REMIND with an elasticity of 0.4 . The regional resolution for the air pollution emission modeling is the REMIND regions (using region-specific emission factors); however, the emission results are then harmonized to country-specific data described in the following section.

Our analysis only considers ambient air pollution. Indoor air pollution is estimated to contribute almost half of all air pollution-related premature deaths (Landrigan et al. 2018) and is therefore a very important factor particularly in developing countries. However, our modeling does not capture the relevant dynamics of e.g. traditional fireplaces. We therefore focus on ambient air pollution. The costs of emission control technologies and the potential induced efficiency penalty are not considered.

\subsection{Atmospheric chemistry transport modeling}

Reconciling the regional resolution of REMIND (12 world regions) and the version of GAINS used (24) with the atmospheric chemistry transport model requires a spatial downscaling. We therefore employ a country- and sector-specific downscaling routine utilizing population- and GDP-based emission intensities and their development based on the convergence method of van Vuuren et al. (2007). In the first step, we calculate country-specific emission intensities relative to the GDP and population for the base year. The GDP and 
population development of the modeling years give an emission intensity growth rate which we then use to calculate the modeling years' emission intensity and emissions. The difference of the sum of country and regional emissions is then distributed accordingly to the countries which gives the final country-specific emission. These emission results are then harmonized through the aneris model (Gidden et al. 2018) to the sector-specific historical emissions of the Community Emissions Data System (CEDS) (Hoesly et al. 2018). In general, the model underestimates 2015 emissions compared with CEDS by around 22\%, which is explained through an incomplete representation of emission-causing activities in the model. Aneris analyzes the historic CEDS results, the model results, and relative difference between the two in the base year 2015. The model then a decision tree to chose the most appropriate harmonization method for each emission, region, and sector.

We employ the global linearized atmospheric chemistry transport model TM5-FASST (Van Dingenen et al. 2018). It is derived through perturbation runs from the full chemical transport model TM5. The model calculates the concentrations for particulate matter $\left(\mathrm{PM}_{2.5}\right)$ and ozone $\left(\mathrm{O}_{3}\right)$ on a $1^{\circ} \times 1^{\circ}$ grid resolution from emission results aggregated to 56 world regions. Included emissions are $\mathrm{SO}_{2}, \mathrm{NO}_{x}$, black carbon (BC), organic matter (OM), $\mathrm{NH}_{3}$, volatile organic carbon (VOC), and $\mathrm{CH}_{4}$ from anthropogenic emissions as well as natural emission sources (sea salt and dust). These natural sources are very high in some very sparsely populated regions, mostly in the Sahara and the Tibetan Plateau. Besides the regional and sectoral harmonization of emissions, the resulting $\mathrm{PM}_{2.5}$ concentrations are harmonized and downscaled to the Data Integration Model for Air Quality (DIMAQ) developed by Shaddick et al. (2018) with output data available from WHO (2016). The model combines ground measurement and satellite data to estimate mean annual $\mathrm{PM}_{2.5}$ concentrations at a high spatial resolution of $0.1^{\circ} \times 0.1^{\circ}$. Spatially explicit multiplicative factors for the base year are calculated for every $0.1^{\circ} \times 0.1^{\circ}$ of the DIMAQ and $1^{\circ} \times 1^{\circ}$ of TM5FAAST grid. These factors are kept constant and applied to the non-base year modeling period. This downscaling leads to an increase of $\mathrm{PM}_{2.5}$-related deaths of $26.5 \%$ in the base year 2015 and $32.5 \%$ in the $2{ }^{\circ} \mathrm{C}$ scenario in 2050 .

\subsection{Health impact assessment}

The health impact assessment is based on the method laid out in Anenberg et al. (2010) with the updated integrated exposure response (IER) model parameters from Burnett et al. (2014). We consider premature mortality attributable to ambient $\mathrm{PM}_{2.5}$ for five major disease endpoints for which particulate matter was considered a risk factor in the Global Burden of Disease study (Cohen et al. 2017); for adults (> 30a), these endpoints are ischemic heart disease (IHD), cerebrovascular disease (stroke), chronic obstructive pulmonary disease (COPD), and lung cancer (LC); and for children under 5, acute respiratory lung infection (ALRI). In line with Burnett et al. (2014), the toxicity of $\mathrm{PM}_{2.5}$ is assumed to differ only with regard to inhaled mass (exposure) and not with $\mathrm{PM}_{2.5}$ composition. $\mathrm{O}_{3}$ related health impact assessment from respiratory disease follows Jerrett et al. (2009). It is based on the seasonal (April-September) average daily 1-h maximum concentration.

The relative risk (RR), which describes the risk relative to the base mortality rate, for $\mathrm{PM}_{2.5}$ concentrations is calculated through the IER functions according to Burnett et al. (2014), the shapes of which are determined by $\alpha_{d}, \gamma_{d}$, and $\delta_{d}$; the disease endpoints $d$ specific results are shown in Fig. 2:

$$
R R_{d, c}=1+\alpha_{d}\left\{\exp \left[-\gamma_{d}\left(c-c_{c f}\right)^{\delta_{d}}\right]\right\}
$$




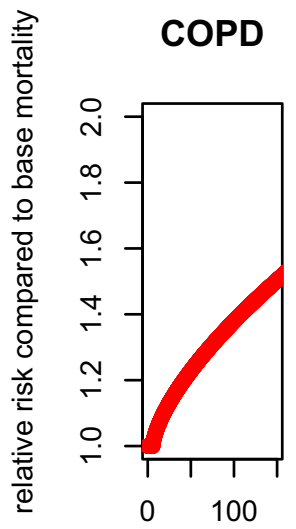

LC

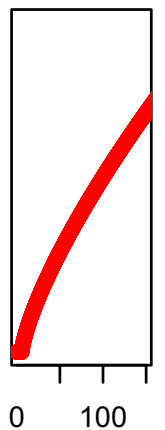

ALRI

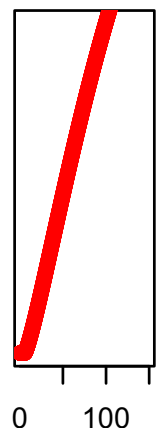

STROKE

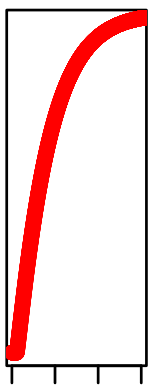

$0 \quad 100$
IHD

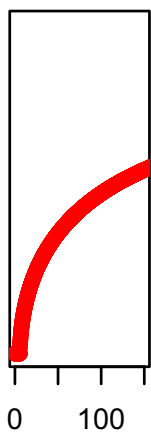

concentration $[\mu \mathrm{g} / \mathrm{m} 3]$

Fig. 2 Integrated exposure response functions describing the relationship between annual mean ambient $\mathrm{PM}_{2.5}$ and relative risk of the five considered disease endpoints. For adults ( $\left.>30 \mathrm{a}\right)$, these endpoints are ischemic heart disease (IHD), cerebrovascular disease (stroke), chronic obstructive pulmonary disease (COPD), and lung cancer (LC); and for children under 5, acute respiratory lung infection (ALRI)

The IER functions have a concave shape and drop to 1 at a concentration $c_{c f}$ of $5.8 \mu \mathrm{g} / \mathrm{m}^{3}$. This theoretical minimal risk is counterintuitive and only a result of a lack of studies with accordingly clean environments. Sensitivity analysis showed that when no theoretical minimal risk is assumed, the health impact is on average $21 \%$ higher across the scenarios. The attributable fraction $a$ is multiplied by the baseline mortality rate $y_{0}$ and exposed population $p$ to obtain the delta of mortality:

$$
\begin{gathered}
a_{d}=\frac{R R_{d}-1}{R R_{d}} \\
\Delta m=\sum_{i=1}^{z} y_{0, d} a_{d} p
\end{gathered}
$$

New research points in the direction of higher health impacts from air pollution. Stanaway et al. (2018) included the effect of air pollution on type 2 diabetes and extended the acute respiratory lung infection assessment for all ages. In combination with recent studies applying a lower theoretical minimum risk concentration (Burnett et al. 2018), our co-benefit analysis can be seen as a conservative estimate.

Cause-specific base data from the WHO data (World Health Organization 2012) for 10 world regions is mapped to the spatial grid. This data is available until 2030; we apply a linear extrapolation for the period until 2050. The base mortality data is not varied across the scenarios. The age structure of the population is taken from KC and Lutz (2017), who supply country-specific projections. We downscale this data uniformly within each country to our spatial grid.

Socioeconomic trends not only play a critical role in evaluating air pollution-related health impacts through their role on the energy system in terms of demand and regional distribution effects, but they also materialize in spatial trends of population development, thus determining the affected cohort by population growth, demographics, redistribution, and migration as well as the clustering in traditionally high pollution areas through urbanization. Recent efforts to develop spatially explicit SSP data facilitate capturing distributional 
effects, relevant for air pollution modelling. In this study, we use the time changing spatial distributions for population of the "middle-of-the-road" SSP2 scenario from Jones and O’Neill (2016) with a resolution of $1 / 8^{\circ}$.

\subsection{Monetizing the health impacts}

In order to relate the health impacts to climate change mitigation costs, they must be translated into a social cost. We employ a willingness-to-pay approach based on a meta-analysis of stated-preference studies by the OECD to estimate the value of a statistical life (VSL) (OECD 2012). VSLs reflect the amount a person is willing to pay to mitigate the mortality risk summed up to one statistical life. Although the stated preference approach is not based on empirical data and therefore comes with the drawbacks of hypotheticality, it can be applied to a large set of the population and policies in contrast to revealed preference methods, which are often based on analysis of the labor market. However, the lack of consistent studies estimating VSLs for all regions of the world necessitates a method to spatially and temporally transfer the employed VSL from the reference region EU-28. We use the unit value transfer method adjusting with GDP PPP per capita $Y$ and an elasticity $\varepsilon$ of 1.2 and 0.8 for countries with lower and higher incomes than the reference region in the base year 2005 (3.6 Mio \$2005). All regional VSLs are in the "VSL.csv" table in the SI.

$$
V S L_{c, t}=V S L_{E U, 2005}{\frac{Y_{c, t}}{Y_{E U, 2005}}}^{\varepsilon}
$$

Intuitively, the VSL should decline with age (less life years lost) and, indeed, there is research pointing to the heterogeneity regarding age (Viscusi 2010). However, there is no comprehensive data on the "senior mortality discount" (Krupnick 2008; Aldy and Viscusi 2007) as well as the "child mortality premium" (Alberini et al. 2010). We consequently apply a uniform VSL regardless of age.

\subsection{Scenario set}

We span the scenario space across two dimensions: climate policy and air pollution control (see Table 1). For climate policies, we model a Reference scenario, the climate policies as currently pledged under the Nationally Determined Contributions (NDC), as well as strengthened efforts (cost-optimal pathways limiting warming to $2{ }^{\circ} \mathrm{C}$ mean global temperature rise by the end of the century). The air pollution scenarios only affect the air pollution emission factors and range from a fixed emission factors (AP_FE) over a middle-of-the-road (AP_trend) to an ambitious (AP_stringent) scenario described in detail below.

The climate policy scenarios are related to the Energy Modeling Forum (EMF)-30 model comparison project scenario "ClimPolicy" for the $2{ }^{\circ} \mathrm{C}$ scenario (Smith et al. this issue). Here, emissions of all GHGs are reduced such that cumulative $\mathrm{CO}_{2}$ emissions until the end of the century lead to limiting global warming below $2{ }^{\circ} \mathrm{C}$ at $50 \%$ probability. The

Table 1 Scenario set

\begin{tabular}{ll}
\hline Climate policy & Air pollution \\
\hline Reference & AP_FE \\
NDC & AP_trend \\
$2{ }^{\circ} \mathrm{C}$ & AP_stringent \\
\hline
\end{tabular}


NDC scenario corresponds to the "Slower-Action" EMF-30 scenario which also implements greenhouse gas reductions that replicate near-term developments consistent with the NDCs. The Reference (Ref) scenario functions as a baseline case where climate policy is taken as the continuation of current legislation and diffusion of pollution control (see Smith et al. (2020), this issue, and Harmsen and et al (2019)). The NDC scenario additionally assumes efficient implementation of the nationally determined contributions, the central element of the Paris Agreement. They are only defined until 2030. Afterwards, a middleof-the road paradigm, in between the extreme cases of comprehensive policy toward the Paris-Agreement long-term targets and backsliding toward the no-policy baseline, has been assumed. Specifically, carbon prices after 2030 gradually converge across regions toward a level of $70 \$ / \mathrm{CO}_{2}$ in 2100. Share targets like the EU's renewable target or China's LowCarbon target are assumed to be gradually tightened over time and technology and policy transfer increased. The $2{ }^{\circ} \mathrm{C}$ scenario achieves a cost-optimal pathway limiting warming to $2{ }^{\circ} \mathrm{C}$ mean global temperature rise by the end of the century through uniform carbon pricing (see SI-1.1.1.)

We explore air pollution control cases ranging from a counterfactual scenario with frozen emission factors on 2015 levels (AP_FE), a middle-of-the-way scenario (AP_trend), to a very optimistic (AP_stringent) scenario (see SI-1.1.2.) building on Riahi et al. (2012) and Rao et al. (2017). The AP_trend scenario was constructed with a world in mind where trends broadly follow their historical patterns. It is determined by an efficient implementation of current near-term policies and a gradual strengthening of goals and technology RDD\&D for high- and medium-income countries (current legislation in 2030 and reaching pessimistic maximal feasible reduction values in 2050) and a delayed progress for low-income countries. The AP_stringent legislation can be seen as an ambitious air pollution control scenario, characterized by increasingly strict and well-enforced policies already in the short term ( $25 \%$ reduction additionally to already planned policies) along with a convergence to the technical maximal feasible reduction in the long term for high- and middle-income countries reaching optimistic maximal feasible reduction values in 2050. Low-income countries are catching up relatively quickly to short-term Western European levels through implicit technology and policy transfer (convergence of emission factors to Western European levels by 2030 and 2050). See Fig. SI-15-21 for a visualization of the emission factors for electricity generation from coal. These AP_stringent scenario can be interpreted as an extension of the EMF-30 "BCOC-EndU" scenario since advances in all sectors are assumed.

\section{Results}

\subsection{Energy-economy-climate}

Figure 3a shows the primary energy mix of the air pollution AP_trend scenario set for the focus regions Europe, China, and India as well as the global aggregate. Corresponding graphs for all world regions as well as for secondary energy and electricity can be found in Supplementary Material (see Fig. SI-2, 4, 5). As an overall trend, more ambitious climate policy is closely tied to a reduced utilization of fossil fuels (especially coal), the expansion of renewables, and the more efficient use of energy.

While Europe is phasing out coal already in the short term under the current NDCs, there is only a marginal effect on the primary energy mix of China and India compared with the reference until 2030. The lack of coal reduction targets in India, in combination with lower demand from other regions, raises the utilization of coal in India relative to reference 
(a) Primary energy supply.
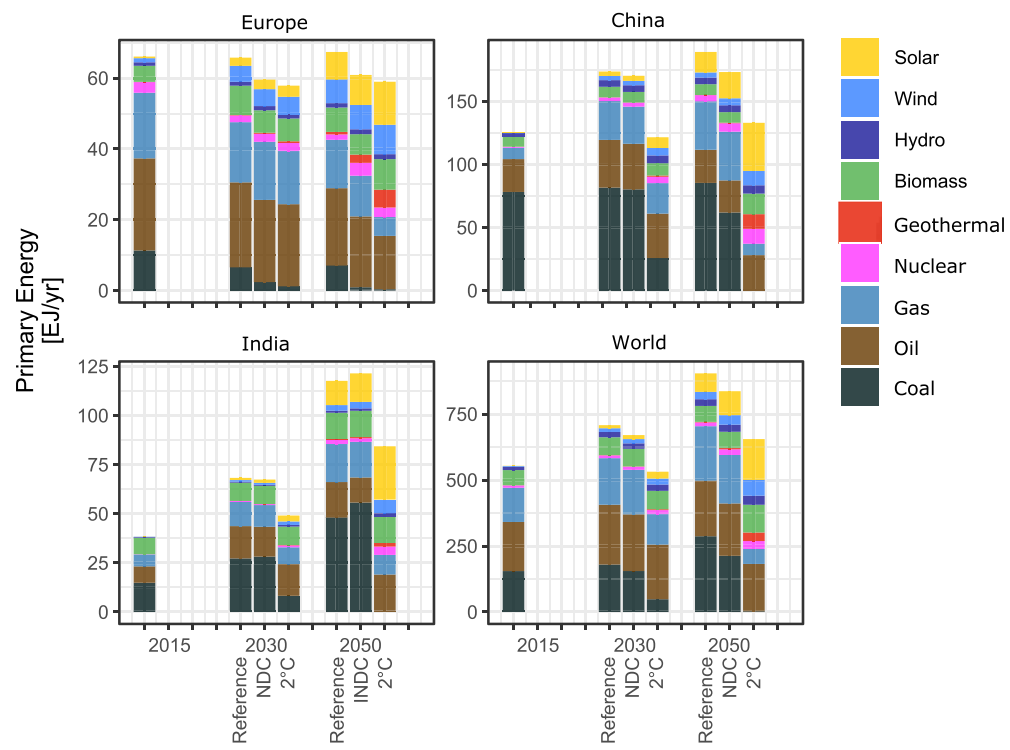

(b) Greenhouse gas emissions- coal related emissions for the NDC in streakline.

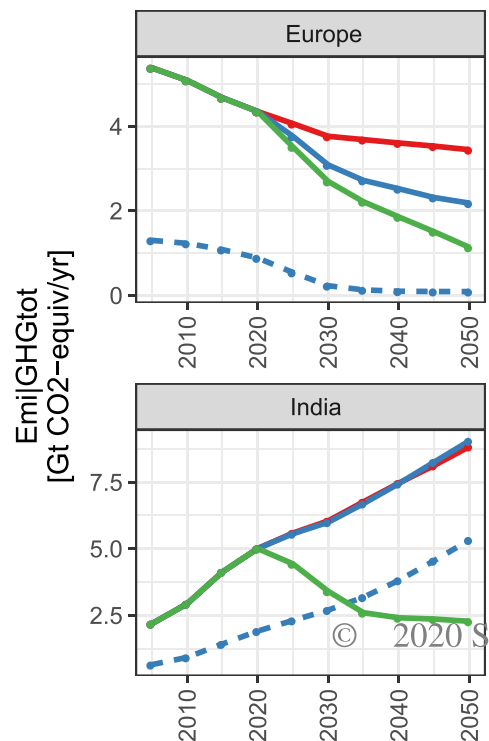

total

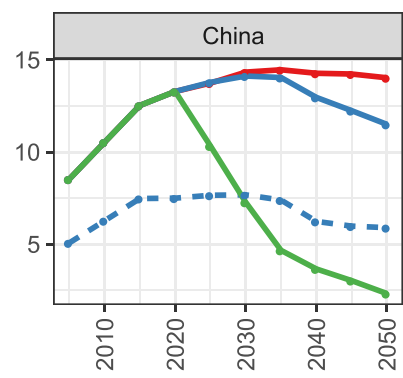

World

Reference $=2 \mathrm{NDC}=2^{\circ} \mathrm{C}$

Fig. 3 Energy-Economy-Climate results of the AP_trend case for the Reference, NDC, and $2{ }^{\circ} \mathrm{C}$ scenario for the focus regions Europe, China, India, and the World in 2015, 2030, and 2050. Greenhouse gas emissions include carbon dioxide $\left(\mathrm{CO}_{2}\right)$, methane $\left(\mathrm{CH}_{4}\right)$, nitrous oxide $\left(\mathrm{N}_{2} \mathrm{O}\right)$, and F-gases. Each gas is weighted by its global warming potential and aggregated to give total greenhouse gas emissions in $\mathrm{CO}_{2}$ equivalents 
(the same applies to Sub-Saharan Africa and the Middle East, North Africa, and Central Asia). The $2{ }^{\circ} \mathrm{C}$ scenario, in contrast, necessitates a profound transformation in all regions, not only entailing an accelerated exit from coal but also a considerably higher utilization of renewables and reduction of energy demand (in the long term). The electricity sector plays a crucial role in the $2{ }^{\circ} \mathrm{C}$ scenario with a quadrupling of demand by 2050, indicating the electrification of other sectors while decarbonizing through a transition to renewables combined with essentially a gas exit (see Supplementary Material Fig. SI-5).

Figure $2 \mathrm{~b}$ shows the corresponding greenhouse gas emission trajectories in $\mathrm{CO}_{2}$ equivalents (see the Supplementary Material Fig. SI-3 for all world regions). As expected, more stringent climate policy leads to lower emissions. However, the current NDCs only achieve a stabilization of 2015 levels, resulting in an end-of-century temperature increase of well above $3{ }^{\circ} \mathrm{C}$. On the other hand, $2{ }^{\circ} \mathrm{C}$ conforming climate policy would significantly reduce GHG emissions until mid-century. The difference between these two scenarios represents the emissions gap identified by United Nations Environment Programme (2018), even assuming efficient implementation of the current NDCs. The need for strengthening the current NDCs with regards to coal is very starkly exemplified in China and India where the coal combustion as allowed by their current NDCs alone would emit more than their total projected emissions in a $2{ }^{\circ} \mathrm{C}$ scenario from 2030 on.

\subsection{Emission and concentrations}

We focus on $\mathrm{SO}_{2}$ and $\mathrm{NO}_{x}$ as primary contributors to air pollution for our visualization of the emission results; comprehensive graphs encompassing the sectors energy, industry, residential commercial, and transport can be found in Supplementary Material (see Fig. SI6-10). We further included the full emission results in the SI data table "emissions.csv." Figure 4 shows the total emissions; the columns correspond to the AP_trend air pollution control scenario with the AP_stringent and AP_FE marked. The effect of air pollution policy and RDD\&D is clearly visible; decreasing emission factors due to air pollution control result in emission reductions in the Ref scenario, despite higher consumption of combustible energy carriers. This suggests that the benefits of climate policy as it relates to air pollution reductions mostly occur before 2050 .

A closer look into the effect of climate policy gives two prominent insights: (1) The current NDCs only have a marginal effect on emission levels compared with the reference. In contrast, the $2{ }^{\circ} \mathrm{C}$ scenario is able to significantly lower emissions, especially the $\mathrm{SO}_{2}$ emissions associated with the combustion of coal. (2) The remaining relatively high $\mathrm{NO}_{x}$ emissions in a $2{ }^{\circ} \mathrm{C}$ world are mainly due to residual emissions from industry and transport (see Supplementary Material Fig. SI-8, 10). Both see rising electrification but only stagnating use of liquid fuels. This highlights that though decarbonizing the energy supply is crucial, the transport and industry sectors hold additional potential for air pollution emission reduction. This is especially relevant due to the concentrated nature of transport emissions such that they are in close proximity to humans in an increasingly urbanized world.

In the regional analysis, we focus on Europe, China, and India as examples of mature and emerging economies. Detailed results for other regions are available in Supplementary Material Fig. SI-6.

Europe, representing a developed region, experiences a drop in emission levels already in the reference scenario due to a reduction of coal and decreasing emission factors, and only comparatively small additional reductions in the climate policy cases. China shows a similar pattern, with a more pronounced reduction in the $2{ }^{\circ} \mathrm{C}$ scenario compared with the Ref and NDC scenarios. However, recent literature has shown that China experiences a 


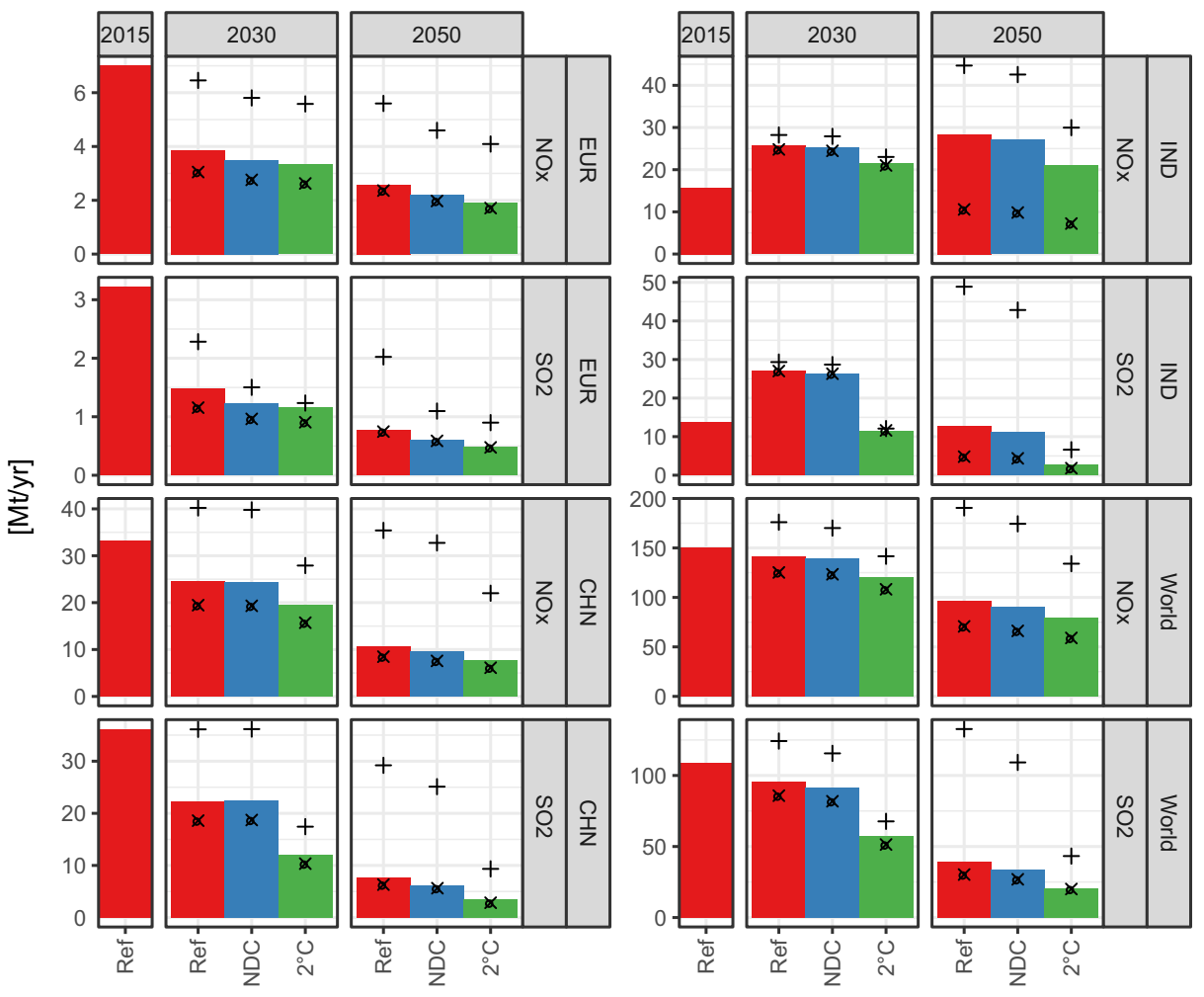

Fig. 4 Total emissions of the air pollutant $\mathrm{SO}_{2}$ and $\mathrm{NO}_{x}$ for the reference, $\mathrm{NDC}$, and $2{ }^{\circ} \mathrm{C}$ scenario for the focus regions Europe, China, India, and the World in 2015, 2030, and 2050. Bars represent values for the AP_trend air pollution control scenario; markers represent the AP_stringent $(\otimes)$ and AP_FE (+) sensitivity cases

steep decrease of $\mathrm{SO}_{2}$ emissions ( $\mathrm{Li}$ et al. 2017) through stricter air pollution control. These recent developments are not included in our emission factor data. The $\mathrm{SO}_{2}$ results for China should therefore be seen as counterfactually high estimates. India, on the other hand, faced rising emissions recently and continues to do so until 2030 in the Ref and NDC scenarios, and only the ambitious climate policy scenario is able to stabilize or reduce the emission levels until 2050.

All other pollutant emissions can be found in the SI emission Table and the Fig. SI-11-21. All species show a similar trend as $\mathrm{SO}_{2}$ and $\mathrm{NO}_{x}$. However, the emissions from grassland burning increase in the ambitious climate policy scenarios compared with the reference case. These emissions are directly liked in the model to higher biomass use.

As mentioned above, the AP_stringent scenario can be seen as an ambitious air pollution control world. In contrasting with the AP_trend scenario, it indicates how robust the differences between the climate policy scenarios are. On a global level, AP_stringent air pollution control can achieve lower emission levels in general, especially mid-century; however, the spread between the NDC and $2{ }^{\circ} \mathrm{C}$ scenarios under stringent pollution controls is similar to the spread under the AP_trend cases. See in Fig. 4 the difference of the different climate policy scenarios between the bars and the difference between the $\otimes$. This supports the argument that synergies of ambitious climate policy are still relevant even under optimistic 
air pollution control. The AP_FE scenario (+) assumes frozen emission factors on 2015 levels and thus isolates the maximal effect of climate policy on air pollutant emissions. It becomes clear that the air quality benefits of the Ref and NDC are much more sensitive to slow progress in air pollution control than the $2{ }^{\circ} \mathrm{C}$ scenario, especially in the short term. In conclusion, climate policy is a hedge against slower air pollution control and tighter air pollution control is a hedge against human health impacts from air pollution of slower climate policy progress.

Figure 5 shows the atmospheric chemistry transport model results for $\mathrm{PM}_{2.5}$ concentrations. Plotted there are the base year and the reference and climate policy scenario results of the year 2050 for the AP_trend air pollution control case. We focused primarily on Europe and Southeast Asia (including China and India); however, results were computed for all land areas, shown in Supplementary Material (Fig. SI-24-26).

The bar chart shows the population fraction exposed to the National Ambient Air Quality Standard of China GB3095-2012 of $35 \mu \mathrm{g} / \mathrm{m}^{3}$ (orange), the EU limit of $20 \mu \mathrm{g} / \mathrm{m}^{3}$ introduced through the directive 2008/50/EC (yellow), and the WHO guideline of $<10 \mu \mathrm{g} / \mathrm{m}^{3}$ (green). The EU threshold was exceeded in most of eastern Europe in 2015, especially in Poland and the Balkans, and also parts of Germany and northern Italy. Only Scandinavia and the Iberian Peninsula had already achieved the WHO guideline. Southeast Asia's starting concentration levels are much higher, with the majority of the population living above the Chinese standard, and pollution hot spots were mainly located in Northern India and Eastern China.

In all scenarios modeled, Europe experiences a decrease of concentrations quite analogous to the emission levels. The population exposed to levels above the $20 \mu \mathrm{g} / \mathrm{m}^{3}$ limit declines from 79 (400 mio) to $19 \%$ (100 mio) already in 2030. In 2050, most of the population is projected to be living under the WHO limit. China also achieves a considerable reduction, especially in the currently highly polluted coastal areas, in the $2{ }^{\circ} \mathrm{C}$ scenario. India, on the other hand, struggles to reduce concentrations and sees only a slight decrease in the NDC compared with the reference scenario. The rising concentrations in the reference and NDC scenarios compared with 2015 levels correspond to the steep rise in economic activity, associated energy demand, and slow progress in air pollution control. Factoring in population growth and urbanization trends, current NDCs would actually lead to an increase from 86 ( 2.6 billion) to $89 \%$ ( 3 billion) living in highly polluted areas $\left(>35 \mu \mathrm{g} / \mathrm{m}^{3}\right)$ in Southeast Asia in 2050 . The $2{ }^{\circ} \mathrm{C}$ scenario, however, is able to slash concentrations to below the Chinese standard for almost half of the Southeast Asian (including China and India) population.

\subsection{Health impacts and cost}

Figure 6 depicts spatially explicit health impacts in terms of annual premature deaths caused by $\mathrm{PM}_{2.5}$ and $\mathrm{O}_{3}$ concentrations of the AP_trend scenario. Across all scenarios, the mortality share of $\mathrm{PM}_{2.5} / \mathrm{O}_{3}$ decreases from $92 \%$ in 2015 to $80 \%$ in 2030 and to around $70 \%$ in 2050 . The base year is plotted in the top map, and the following rows show the differential of each scenario to the base year. The results for all other regions are in Supplementary Material (Fig. SI-13-15).

The reference scenario only has a reduction effect in Europe where stricter air pollution control and some switch from fossils to renewables are occurring without additional climate policies. The $2{ }^{\circ} \mathrm{C}$ scenario avoids an aggregated premature death toll of 1.1 million people in 2050 alone compared with the reference case. The current NDCs, on the other hand, only yield a benefit of 130,000 avoided premature deaths. 
(a) Europe
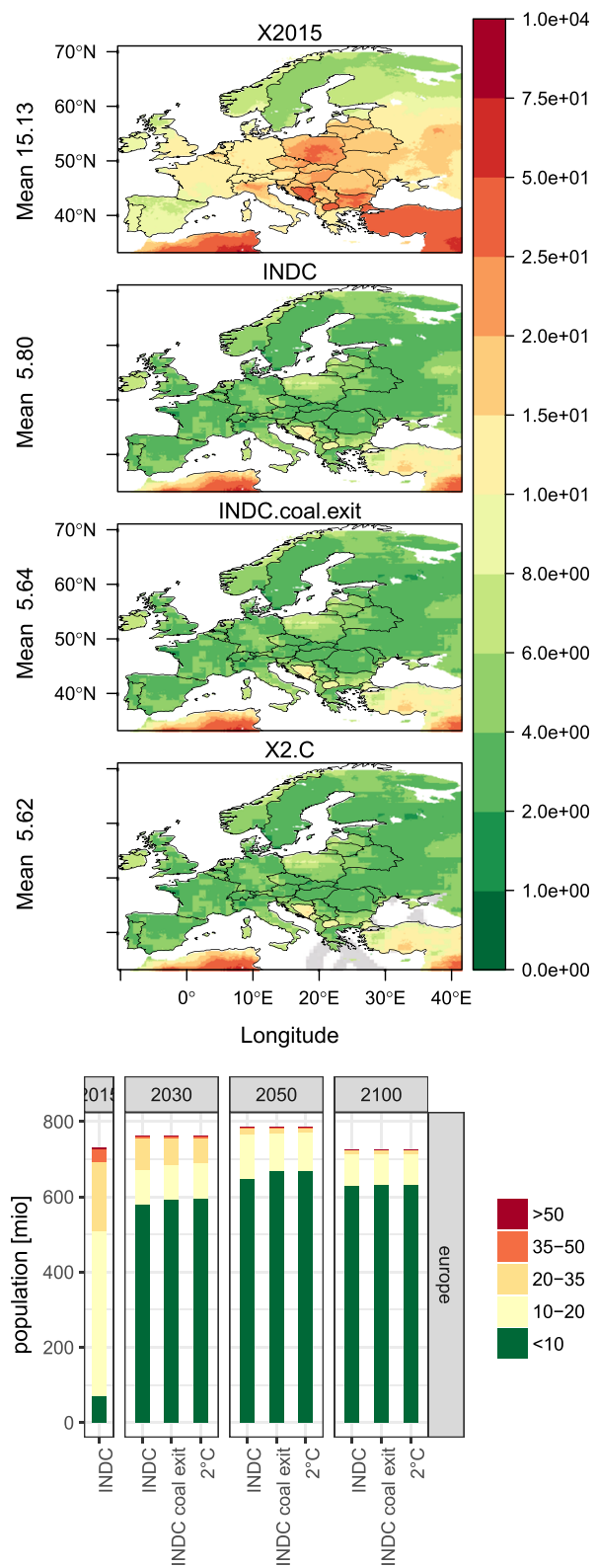

(b) Southeast Asia
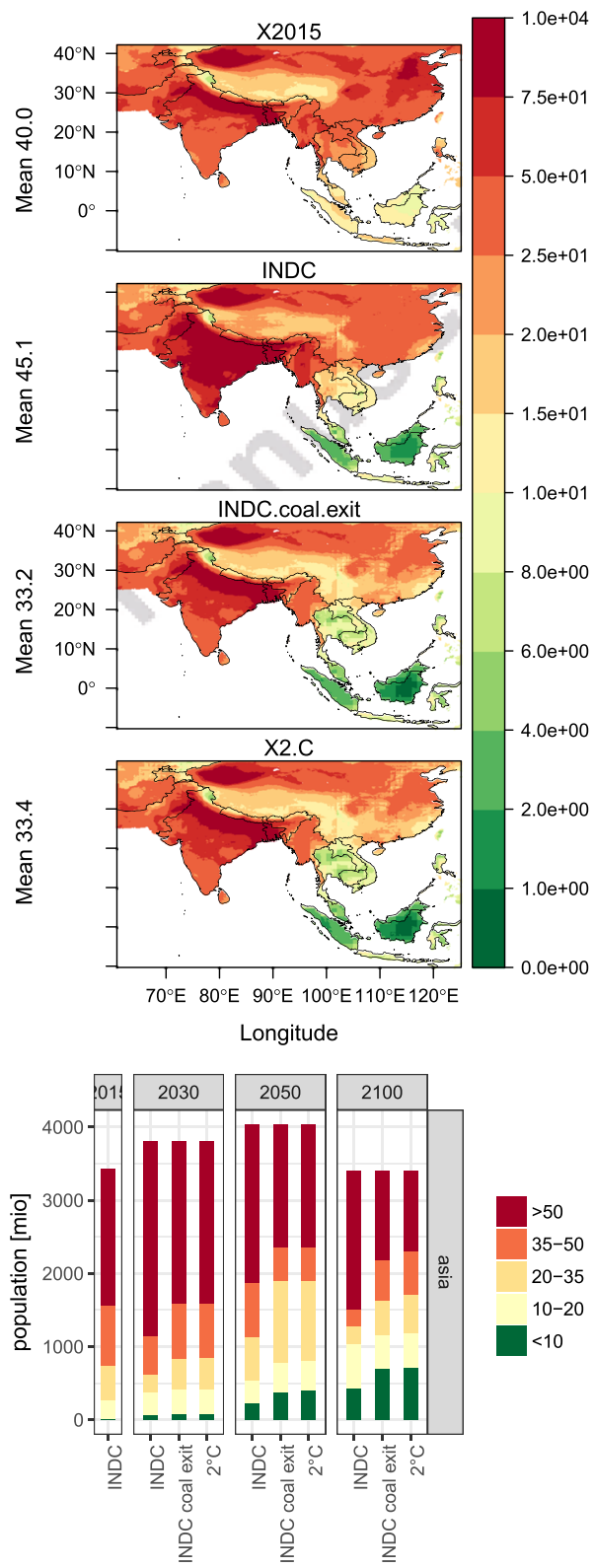

Fig. 5 Mean annual $\mathrm{PM}_{2.5}$ concentration $\left(\mu \mathrm{g} / \mathrm{m}^{3}\right)$ for the years 2015 and 2050 under the NDC and $2{ }^{\circ} \mathrm{C}$ scenarios with the AP_trend air pollution control case for Europe and Southeast Asia. Bars represent the population living under concentrations of $>50 \mu \mathrm{g} / \mathrm{m}^{3}$ (red), $50>x>35 \mu \mathrm{g} / \mathrm{m}^{3}$ (orange), $35>\times>20 \mu$ $\mathrm{g} / \mathrm{m}^{3}$ (light orange), $20>\times>10 \mu \mathrm{g} / \mathrm{m}^{3}$ (yellow), and $<10 \mu \mathrm{g} / \mathrm{m}^{3}$ (green) 
(a) Spatially explicit health impact in terms of annual premature deaths in cases $/ \mathrm{km}^{2}$
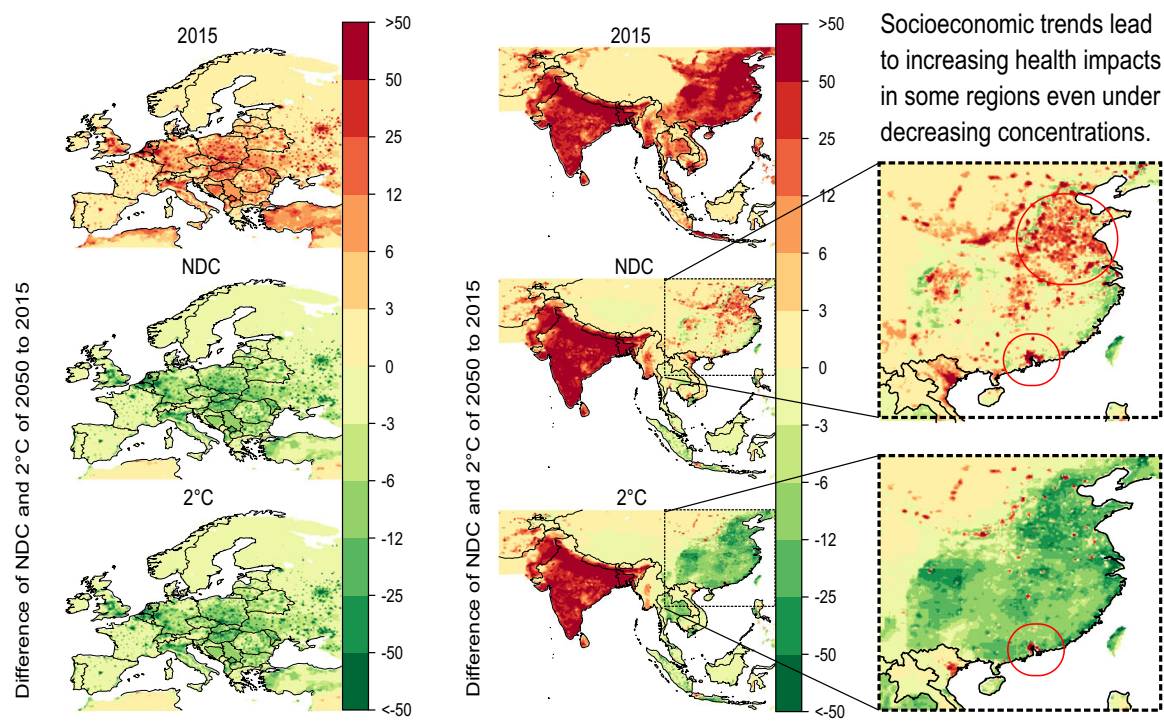

(b) Bars represent premature deaths for the AP_trend air pollution control scenario, markers represent values in the $\mathrm{AP} \_$stringent $(\otimes)$ and $\mathrm{AP} \_\mathrm{FE}(+)$ sensitivity cases in million cases per year.
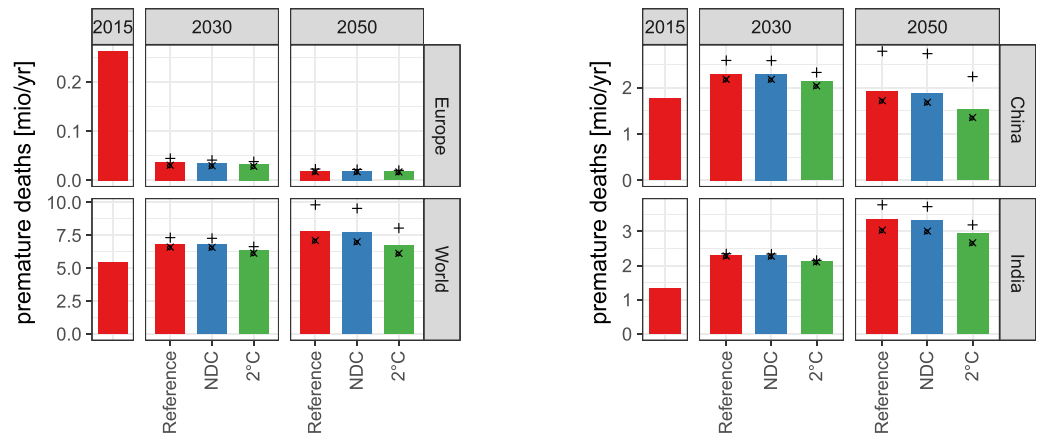

Fig. 6 Health impact of $\mathrm{PM}_{2.5}$ and $\mathrm{O}_{3}$ for Europe and Southeast Asia for the year 2015 and relative to 2015 for the year 2050 under the $\mathrm{NDC}$ and $2{ }^{\circ} \mathrm{C}$ scenarios with the AP_trend air pollution control case. Zoomed into areas where socioeconomic trends lead to increasing health impacts even under decreasing concentrations

The 2015 air pollution-related mortality in China of more than 1.7 million deaths ( 80 per 100k inhabitants) highlights the urgency of air pollution reductions; however, the modeling shows that it is a major challenge to reduce the health impact despite lower air pollution concentrations. In fact, the health impact is rising in 2030 in all scenarios and only the $2{ }^{\circ} \mathrm{C}$ scenario is able to lower the impact in 2050 , with the exemption of few high population areas seeing rising premature deaths even under ambitious climate policy due to socioeconomic effects, highlighted in the magnified maps. India is confronted with a similarly severe air pollution crisis, facing 1.3 (99 per 100k inhabitants) million premature deaths in 2015. This number is more than doubled in the reference scenario until 2050 with minor mitigation effects of the current NDCs. Thus, it becomes apparent that India is facing major 
challenges due to socioeconomic trends even in a $2{ }^{\circ} \mathrm{C}$ scenario, which is reducing the deaths by 500,000 (28 per 100k inhabitants) annually in 2050. (India sees a doubling of the population over 30 years until 2050 and an increase in urbanization from 30 to $53 \%$.)

The AP_stringent and AP_FE scenarios show the magnitude of health impact under ambitious or non-progressing air pollution policy. They significantly affect the health impact with up to 10 million premature deaths globally in the AP_FE reference scenario, of which most of the burden is on China. This highlights that the air pollution control is assumed to be developing quite rapidly in China in the AP_trend case. Despite shifting the results, Fig. 6 shows that the differential between the Ref and $2{ }^{\circ} \mathrm{C}$ scenario does not change significantly under AP_stringent air pollution control in China, India, and globally. This again supports the argument that synergies of ambitious climate policy are still relevant even under optimistic air pollution control.

Figure 7 shows the discounted (5\%) climate change mitigation costs (as consumption losses relative to the reference adjusted for changes in current accounts as described in Aboumahboub et al. (2014)), air quality benefits (as social cost), and resulting net synergies until 2050 as a differential to the reference case. Although these are not the same type of cost, we compare them to illustrate the magnitude of air pollution-related co-benefits. We extend the analysis here with Middle East, North Africa, and Central Asia (MEA) as a representative of energy-exporting regions and Sub-Saharan Africa (excl. South Africa) as a developing region. The cost calculation for all world regions can be found in Supplementary Material (Fig. SI-16). Importantly, the analysis only considers the costs of climate change mitigation, but does not account for avoided climate damages.

From a global social cost perspective, we robustly find net positive effects from $2{ }^{\circ} \mathrm{C}$ conforming climate policies across air pollution scenarios with a global benefit equal to $0.08 \%$ of GDP until 2050 (in line with Vandyck et al. (2018)). In other words, the higher mitigation costs of strengthening the current NDCs to a $2{ }^{\circ} \mathrm{C}$ compatible climate policy are more than compensated by the associated lower health impacts. Especially the emerging countries China and India see an illustrative net benefit of equal to $1.5 \%$ and $0.5 \%$ of GDP (in line with regional literature Li et al. (2018)). The current NDCs on the other hand come with much less air pollution benefits which, in combination with still significant mitigation cost, result in a global net negative effect equal to $-0.18 \%$ of GDP (almost cost neutral for China and $+0.1 \%$ for India).

However, the regional analysis presents a more diverse picture. Europe, as a developed region, already reduces air pollution in the reference case through ambitious air pollution legislation, which results in low additional benefits of the climate policy scenarios. Nevertheless, the $2{ }^{\circ} \mathrm{C}$ scenario yields the highest illustrative net benefits due to a negative mitigation cost. Here, a combined effect of reduced prices for fossil fuels results in lower variable and fixed energy system cost. Combining only small consumption losses from GDP effects compared with the developing countries results in a negative mitigation cost (see Fig. SI-1 for a decomposition of mitigation cost in 2030). China and India, as hot spots of air pollution, on the other hand, strongly benefit from climate policy-induced improvements in air quality compared with the mitigation cost. The situation is flipped in fossil fuelexporting regions such as MEA; here, the $2{ }^{\circ} \mathrm{C}$ scenario inflicts high mitigation costs with limited air pollution benefits. Sub-Saharan Africa, as a developing region, is confronted with a relatively high mitigation cost because of the high carbon intensity of economic output in combination with limited air quality co-benefits.

The AP_FE and AP_stringent scenarios can be interpreted as sensitivities of the cobenefits of climate policies to the progression of air pollution policies. We find that slower 


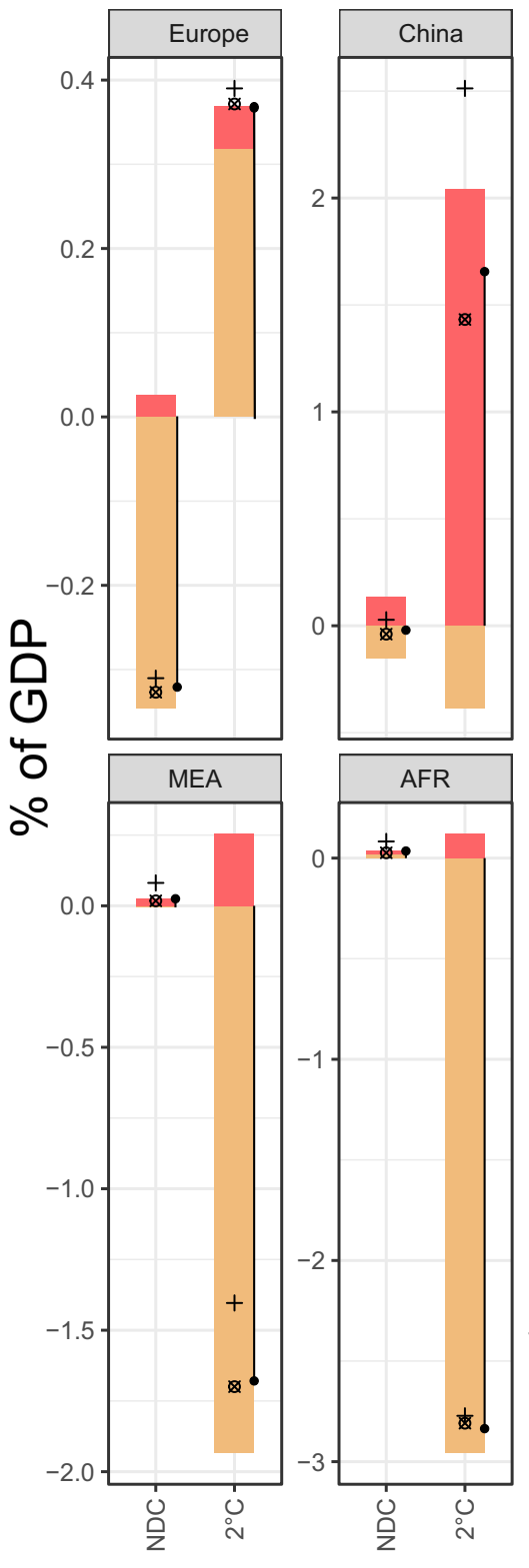

Health benefits

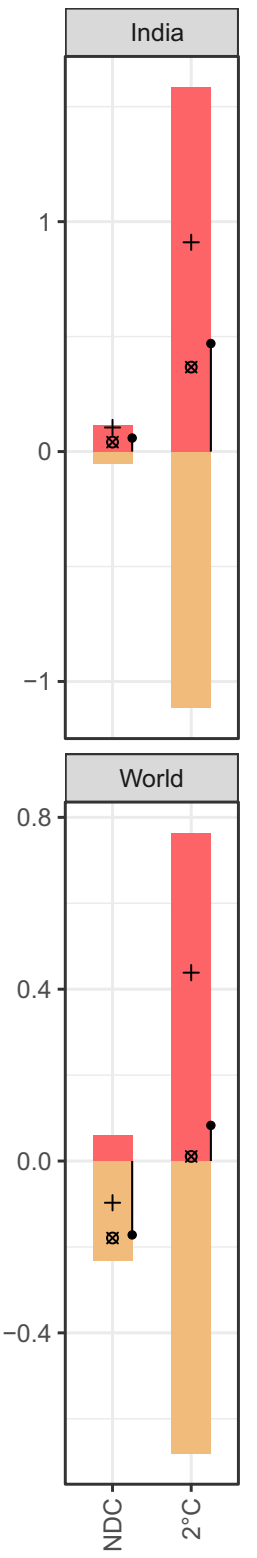

Mitigation cost

\section{Synergies}

\section{$i$ Trend + FE Stringent}

Fig. 7 Climate change mitigation costs (yellow), monetized avoided health damages (red) and net social costs for the AP_trend $(\bullet)$, AP_stringent $(\otimes)$, and AP_FE (+) cases. Amounts are cumulated over 2015-2050, discounted at $5 \%$ and expressed relative to cumulated and discounted GDP PPP 
air pollution control, represented by the AP_FE scenario, strongly increases the air pollution benefits and leads to even higher illustrative net benefits than the AP_trend scenario. On a global level, the AP_stringent air pollution control scenario lowers the illustrative net benefits compared with the AP_trend, but they are still positive.

\section{Discussion}

Climate change and air pollution are both pressing and interconnected issues on a global scale with different regional manifestations. The purpose of this study was to assess the synergies from climate change mitigation policies on reduced health impacts of air pollution under different air pollution control scenarios. We analyzed the current NDCs and a $2{ }^{\circ} \mathrm{C}$ consistent climate policy scenario, focusing on the coherent translation of assumptions and data in all modeling steps such as socioeconomic trends, crucial for the health impact of air pollution. The goal was to quantify the air pollution health impacts and relate them to climate mitigation cost.

In line with United Nations Environment Programme (2018), we find the current NDCs to clearly fall short of achieving a decarbonization suitable to limit climate change to the goals of the Paris Agreement. The NDCs consequently also do not lead to substantial air pollution concentration reduction in China and India compared with the reference, or in Europe where air pollution policies lower concentrations already in the reference scenario.

Increasing the stringency of climate policy to a $2{ }^{\circ} \mathrm{C}$ conforming pathway significantly raises the mitigation costs compared with the NDCs on a global level; however, these costs are compensated by the air quality health benefits. Or to put it differently, the illustrative net social benefit of weak action, as reflected by the NDC scenario, is lower than the illustrative net social benefit of $2{ }^{\circ} \mathrm{C}$ conforming action, already with a narrow focus on air pollution and not even considering the monetary damages from climate change impacts. This holds as a global aggregate but is especially relevant for China and India which benefit from strengthening their NDCs with an aggregated illustrative net benefit equal to $1.5 \%$ and $0.5 \%$ of GDP until 2050. Developed regions (Europe, USA, and Japan) on the other hand have comparatively low additional air pollution benefits from ratcheting up their NDCs to $2{ }^{\circ} \mathrm{C}$ conforming mitigation. Nevertheless, the negative mitigation costs in the $2{ }^{\circ} \mathrm{C}$ scenario result in illustrative net benefits also for these regions; only fossil fuels-exporting regions face high mitigation costs and low air pollution benefits.

The assessment of different air pollution control scenarios shows the illustrative net benefits to be potentially much higher if non-effective enforcement of control policies and slower technological progress are assumed, making climate policy a hedge against slow air pollution control. Current developments, for example concerning the road transport sector, suggest the relevance of both such non-effective enforcement and slow progress (Anenberg et al. 2017). Under the assumption of faster and more ambitious adoption of advanced air pollution control, the synergies are lower but still positive for a $2{ }^{\circ} \mathrm{C}$ scenario. However, it is important to note that lower co-benefits do not mean stringent air pollution control should not be implemented. Our results show considerable remaining health impacts in the AP_trend and even AP_stringent scenario; therefore, all measures should be taken to enhance air quality.

We further find that while the $2{ }^{\circ} \mathrm{C}$ conforming transformation of the energy supply sector substantially reduces air pollution, socioeconomic and spatial trends pose a major challenge to countries with dramatic increases in population, urbanization, and GDP, such 
as India and parts of China. This, in combination with our finding of only slowly decreasing air pollutant emissions compared with 2015 levels in sectors such as transport and industry, emphasizes the need for further research that extends the current ex-post-assessment of climate policy scenarios to a dynamic approach. This would allow analyzing how to optimally exploit climate policy and air pollution control sector, region and time specific, deriving transformation pathways that maximize co-benefits.

Funding information Open Access funding provided by Projekt DEAL. The research leading to these results was supported by the INTEGRATE and ENavi projects funded by the German Federal Ministry of Education and Research (BMBF) and by the European Union's Horizon 2020 research and innovation program under grant agreement No 730403 (INNOPATHS).

Open Access This article is licensed under a Creative Commons Attribution 4.0 International License, which permits use, sharing, adaptation, distribution and reproduction in any medium or format, as long as you give appropriate credit to the original author(s) and the source, provide a link to the Creative Commons licence, and indicate if changes were made. The images or other third party material in this article are included in the article's Creative Commons licence, unless indicated otherwise in a credit line to the material. If material is not included in the article's Creative Commons licence and your intended use is not permitted by statutory regulation or exceeds the permitted use, you will need to obtain permission directly from the copyright holder. To view a copy of this licence, visit http://creativecommonshorg/licenses/by/4.0/.

\section{References}

Alberini A, Bateman I, Loomes G, Ščasný M (2010) Valuation of environment-related health risks for children. OECD Publishing

Aldy JE, Viscusi WK (2007) Age differences in the value of statistical life: revealed preference evidence. Rev Environ Econ Policy 1:241-260. https://doi.org/10.1093/reep/rem014

Amann M (2012) Greenhouse gas and air pollution interaction and synergies (GAINS). 0-43

Anenberg SC, Horowitz LW, Tong DQ, West JJ (2010) An estimate of the global burden of anthropogenic ozone and fine particulate matter on premature human mortality using atmospheric modeling. Environ Health Perspect 118:1189-1195. https://doi.org/10.1289/ehp.0901220

Anenberg SC, Miller J, Minjares R et al (2017) Impacts and mitigation of excess diesel-related NO x emissions in 11 major vehicle markets. Nature 545:467-471. https://doi.org/10.1038/nature22086

Bauer N, Edenhofer O, Kypreos S (2008) Linking energy system and macroeconomic growth models. Comput Manag Sci 5:95-117. https://doi.org/10.1007/s10287-007-0042-3

Bauer N, Baumstark L, Leimbach M (2012) The REMIND-R model: the role of renewables in the low-carbon transformation-first-best vs. second-best worlds. Clim Change 114:145-168. https://doi.org/10.1007/s10584-011-0129-2

Burnett R, Chen H, Szyszkowicz M et al (2018) Global estimates of mortality associated with long-term exposure to outdoor fine particulate matter. Proc Natl Acad Sci 115:9592-9597. https://doi.org/10.1073/pnas.1803222115

Burnett RT, Arden Pope C, Ezzati M et al (2014) An integrated risk function for estimating the global burden of disease attributable to ambient fine particulate matter exposure. Environ Health Perspect 122:397403. https://doi.org/10.1289/ehp.1307049

Cohen AJ, Brauer M, Burnett R et al (2017) Estimates and 25-year trends of the global burden of disease attributable to ambient air pollution: an analysis of data from the Global Burden of Diseases Study 2015. The Lancet 389:1907-1918. https://doi.org/10.1016/S0140-6736(17)30505-6

Deng HM, Liang QM, Liu LJ, Anadon LD (2017) Co-benefits of greenhouse gas mitigation: a review and classification by type, mitigation sector, and geography. Environmental Research Letters 12. https://doi.org/10.1088/1748-9326/aa98d2

Duncan G (2014) After neo-liberalism, what could be worse? N Z Sociol 29:15-39. https://doi.org/10. 1073/pnas.1809474115

Gao J, Kovats S, Vardoulakis S et al (2018) Science of the total environment public health cobenefits of greenhouse gas emissions reduction: a systematic review. Sci Total Environ 627:388-402. https://doi.org/10.1016/j.scitotenv.2018.01.193 
Gidden MJ, Fujimori S, van den Berg M et al (2018) A methodology and implementation of automated emissions harmonization for use in integrated assessment models. Environ Model Softw 105:187-200. https://doi.org/10.1016/j.envsoft.2018.04.002

Harmsen M et al (2019) Taking some heat off the NDCs? The limited potential of additional short-lived climate forcers' mitigation. Climatic Change. https://doi.org/10.1007/s10584-019-02436-3

Heft-Neal S, Burney J, Bendavid E, Burke M (2018) Robust relationship between air quality and infant mortality in Africa. Nature 559:254-258. https://doi.org/10.1038/s41586-018-0263-3

Hoesly RM, Smith SJ, Feng L et al (2018) Historical (1750-2014) anthropogenic emissions of reactive gases and aerosols from the community emissions data system (CEDS). Geosci Model Develop 11:369-408. https://doi.org/10.5194/gmd-11-369-2018

Jerrett M, Burnett RT, Pope CA et al (2009) Long-term ozone exposure and mortality. New England J Med 360:1085-1095. https://doi.org/10.1056/NEJMoa0803894

Jones B, O’Neill BC (2016) Spatially explicit global population scenarios consistent with the shared socioeconomic pathways. Environ Res Lett 11:084003. https://doi.org/10.1088/1748-9326/11/8/084003

KC S, Lutz W (2017) The human core of the shared socioeconomic pathways: population scenarios by age, sex and level of education for all countries to 2100. Global Environ Change 42:181-192. https://doi.org/10.1016/j.gloenvcha.2014.06.004

Krupnick A (2008) Mortality-risk valuation and age: stated preference evidence. Ssrn 1:261-282. https://doi.org/10.1093/reep/rem016

Landrigan PJ, Fuller R, Acosta NJ et al (2018) The Lancet commission on pollution and health. The Lancet 391:462-512. https://doi.org/10.1016/S0140-6736(17)32345-0

Leimbach M, Bauer N, Baumstark L, Edenhofer O (2010) Mitigation costs in a globalized world: climate policy analysis with REMIND-R. Environ Model Assess 15:155-173. https://doi.org/10.1007/s10666-009-9204-8

Li C, McLinden C, Fioletov V et al (2017) India is overtaking china as the world's largest emitter of anthropogenic sulfur dioxide. Sci Rep 7:1-7. https://doi.org/10.1038/s41598-017-14639-8

Li M, Zhang D, Li C-T et al (2018) Air quality co-benefits of carbon pricing in China. Nat Clim Change 8:398-403. https://doi.org/10.1038/s41558-018-0139-4

Luderer G, Bertram C, Calvin K et al (2016) Implications of weak near-term climate policies on long-term mitigation pathways. Clim Change 136:127-140. https://doi.org/10.1007/s10584-013-0899-9

Markandya A, Sampedro J, Smith SJ et al (2018) Health co-benefits from air pollution and mitigation costs of the Paris Agreement: a modelling study. The Lancet Planetary Health 2:e126-e133. https://doi.org/10.1016/S2542-5196(18)30029-9

OECD (2012) Mortality risk valuation in environment, health and transport policies. OECD Publishing

O'Neill BC, Kriegler E, Ebi KL et al (2017) The roads ahead: narratives for shared socioeconomic pathways describing world futures in the 21st century. Glob Environ Chang 42:169-180. https://doi.org/10.1016/j.gloenvcha.2015.01.004

Rafaj P, Schöpp W, Russ P et al (2012) Co-benefits of post-2012 global climate mitigation policies. https://doi.org/10.1007/s11027-012-9390-6

Rao S, Klimont Z, Leitao J et al (2016) A multi-model assessment of the co-benefits of climate mitigation for global air quality. Environ Res Lett 11:124013. https://doi.org/10.1088/1748-9326/11/12/124013

Rao S, Klimont Z, Smith SJ et al (2017) Future air pollution in the Shared Socio-economic Pathways. Glob Environ Chang 42:346-358. https://doi.org/10.1016/j.gloenvcha.2016.05.012

Riahi K, Dentener F, Gielen D et al (2012) Energy pathways for sustainable development. In: Johansson TB, Nakicenovic N, Patwardhan A, Gomez-Echeverri L (eds) Global energy assessment (GEA). Cambridge University Press, Cambridge, pp 1205-1306

Shaddick G, Thomas ML, Green A et al (2018) Data integration model for air quality: a hierarchical approach to the global estimation of exposures to ambient air pollution. J R Stat Soc Series C: Appl Stat 67:231253. https://doi.org/10.1111/rssc. 12227

Smith SJ, Chateau J, Dorheim K et al (2020) Impact of methane and black carbon mitigation on forcing and temperature : a multi-model scenario analysis. this issue

Stanaway JD, Zhou M, Zimsen SRM et al (2018) Global, regional, and national comparative risk assessment of 84 behavioural, environmental and occupational, and metabolic risks or clusters of risks for 195 countries and territories, 1990-2017: a systematic analysis for the Global Burden of Disease Stu. The Lancet 392:1923-1994. https://doi.org/10.1016/S0140-6736(18)32225-6

The Lancet Neurology (2018) Air pollution and brain health: an emerging issue. The Lancet Neurology 17:117. https://doi.org/10.1016/S1474-4422(17)30462-3

United Nations Environment Programme (2018) UNEP (2018) The Emissions Gap Report 2018. United Nations Environment Programme, Nairobi 
Van Dingenen R, Dentener F, Crippa M et al (2018) TM5-FASST: a global atmospheric source-receptor model for rapid impact analysis of emission changes on air quality and short-lived climate pollutants. Atmos Chem Phys 18:16173-16211. https://doi.org/10.5194/acp-18-16173-2018

van Vuuren DP, Lucas PL, Hilderink H (2007) Downscaling drivers of global environmental change: enabling use of global SRES scenarios at the national and grid levels. Glob Environ Chang 17:114-130. https://doi.org/10.1016/j.gloenvcha.2006.04.004

Vandyck T, Keramidas K, Kitous A et al (2018) Air quality co-benefits for human health and agriculture counterbalance costs to meet Paris Agreement pledges. Nat Commun 9:1-11. https://doi.org/10.1038/s41467-018-06885-9

Viscusi WK (2010) The heterogeneity of the value of statistical life: introduction and overview. J Risk Uncertain 40:1-13. https://doi.org/10.1007/s11166-009-9083-z

Wang H, Naghavi M, Allen C (2016) Global, regional, and national life expectancy, all-cause mortality, and cause-specific mortality for 249 causes of death, 1980-2015: a systematic analysis for the Global Burden of Disease Study 2015. The Lancet 388:1459-1544. https://doi.org/10.1016/S0140-6736(16)31012-1

West JJ, Smith SJ, Silva RA et al (2013) Co-benefits of mitigating global greenhouse gas emissions for future air quality and human health. Nat Clim Change 3:885-889. https://doi.org/10.1038/nclimate2009

WHO (2016) Modelled global ambient air pollution estimates

World Health Organization (2012) WHO mortality database

Xie Y, Dai H, Xu X et al (2018) Co-benefits of climate mitigation on air quality and human health in Asian countries. Environ Int 119:309-318. https://doi.org/10.1016/j.envint.2018.07.008

Publisher's note Springer Nature remains neutral with regard to jurisdictional claims in published maps and institutional affiliations. 